\title{
TR4 nuclear receptor increases prostate cancer invasion via decreasing the miR-373-3p expression to alter TGF $\beta$ R2/p- Smad3 signals
}

\author{
Xiaofu Qiu ${ }^{1,2, *}$, Jin Zhu ${ }^{3, *}$, Yin Sun ${ }^{2}$, Kun Fan ${ }^{1,2}$, Dong-Rong Yang ${ }^{3}$, Gonghui $\mathbf{L i}^{4}$, \\ Guosheng Yang ${ }^{1,2}$, Chawnshang Chang ${ }^{2,5}$ \\ ${ }^{1}$ Department of Urology, Guangdong No. 2 Provincial People's Hospital, Guangzhou, China \\ ${ }^{2}$ George Whipple Lab for Cancer Research, Departments of Pathology, Urology, Radiation Oncology, and The Wilmot Cancer \\ Center, University of Rochester Medical Center, Rochester, NY, USA \\ ${ }^{3}$ Department of Urology, the Second Affiliated Hospital of Soochow University, Suzhou, China \\ ${ }^{4}$ Chawnshang Chang Liver Cancer Center, Department of Urology, Sir Run-Run Shaw Hospital, Zhejiang University, \\ Hangzhou, China \\ ${ }^{5}$ Sex Hormone Research Center, China Medical University/Hospital, Taichung, Taiwan \\ *These authors have contributed equally to this work \\ Correspondence to: \\ Guosheng Yang, e-mail: 2008yangguosheng@sina.com \\ Chawnshang Chang, e-mail: chang@urmc.rochester.edu \\ Keywords: TR4, prostate cancer, metastasis, miR-373-3p \\ Received: January 07, $2015 \quad$ Accepted: April 14, $2015 \quad$ Published: April 27, 2015
}

\section{ABSTRACT}

Testicular nuclear receptor 4 (TR4), a member of the nuclear receptor superfamily, may play important roles to modulate the metabolic diseases and prostate tumorigenesis. Here we found TR4 could increase prostate cancer (PCa) cell invasion. Mechanism dissection revealed that TR4 might increase PCa cell invasion via decreasing the miR-373-3p expression that resulted in the activation of the TGFBR2/p-Smad3 signals. The in vivo mouse model using orthotopically xenografted CWR22Rv1 cell line transfected with luciferase-reporter confirmed in vitro cell line studies showing TR4 increased PCa metastasis via decreasing the miR-373-3p expression. Together, these data suggest that TR4 may increase PCa metastasis via a newly identified signal and targeting these TR4/miR-473-3p/TGF $\beta R 2 / p-S m a d 3$ signals using TR4 antagonist or TR4-siRNA or miR-373-3p may allow us to develop a new potential therapeutic approach to better suppress PCa metastasis.

\section{INTRODUCTION}

Prostate cancer (PCa) has the second highest mortality in men [1]. Most patients eventually relapse with recurrent metastatic $\mathrm{PCa}$ that has become castration resistant after androgen deprivation therapy (ADT) [2-4]. Identifying molecules and signals linked to enhanced PCa metastasis and development of new therapies to suppress the metastatic PCa may help us to better inhibit the PCa at the later castration resistant stage.

The testicular nuclear receptor 4 (TR4) is a transcriptional regulator that belongs to the nuclear receptor superfamily [5-8]. In vivo mouse studies suggested that TR4 might play important roles to modulate the progression of several diseases including metabolic disorders and various tumors [9-11]. Early studies revealed that TR4 might play a protective role to inhibit the prostate tumorigenesis and knocking-out TR4 in a mouse model (TR4KO) might increase PIN and/or prostatic carcinoma formation [12]. The role of TR4 in PCa metastasis, especially involving the regulation of microRNAs (miRNAs), however, remains to be further elucidated.

TGF $\beta / \mathrm{Smad} 3$ signals play a critical role in the regulation of tumor progression including metastasis [13]. Interestingly, depending on different cellular contexts, TGF $\beta$ might either promote or suppress tumor progression [14], and TGF $\beta$ receptor II (TGF $\beta$ R2) tranduces TGF $\beta$ signaling. miRNAs are small $(<22 \mathrm{nt})$, non-coding RNA molecules that bind to the $3^{\prime}$ untranslated region ( $3^{\prime}$ UTR) of their target mRNAs, 
to regulate gene expression at a post-transcriptional level [15]. More than 1,400 human miRNA sequences have been identified thus far and many of them have been linked to the cancer pathogenesis, including tumor initiation, proliferation and invasion [16]. Importantly, Walter et al. reported that differential profiles of miRNAs might play different roles that are linked to the aggressive behavior of PCa progression [17].

In this study, we found TR4 might be able to function through suppression of the miR-373-3p expression to alter the TGF $\beta$ R $2 / \mathrm{p}-\mathrm{Smad} 3$ signals to enhance the PCa cell invasion.

\section{RESULTS}

\section{TR4 increases PCa cell invasion}

An early study [18] indicated the higher TR4 expression in tumor tissues of PCa patients with Gleason score $5+4$ compared with those patients with Gleason score $3+3$. Interestingly, using NCBI GEO databases [19] to analyze the PCa sample array with TR4 expression, we found that PCa metastatic tumors have a slightly higher TR4 expression than PCa localized tumors $(p<0.001)$ (Figure 1A).

We then applied 3 PCa cell lines, including C4-2, PC3 and CWR22Rv1, to confirm this clinical finding, and results revealed that TR4 was differentially expressed in these PCa cell lines with higher expression in PC3 and lower expression in CWR22Rv1 cells (Figure 1B). Importantly, using matrigel coated transwell invasion assays with TR4-shRNA to knock down TR4 in PC3 cells, we found that reduced TR4 decreased PCa cell invasion (Figure 1C). Similar results were also obtained when we replaced PC3 cells with C4-2 cells (Figure 1D). We also applied an opposite approach with addition of functional TR4-cDNA into CWR22Rv1 cells, and results revealed that increased TR4 significantly increased PCa cell invasion (Figure 1E).

Together, results from Figure $1 \mathrm{~A}-1 \mathrm{E}$ proved TR4 might play positive roles to increase the PCa cell invasion.

\section{TR4 decreases miR-373-3p expression in PCa cells}

To dissect the potential mechanism(s) by which TR4 can increase PCa cell invasion, we examined if TR4 might function through modulation of the miRNAs to increase PCa cell invasion as recently accumulating evidences [18] suggested that some selective miRNAs might be able to alter PCa metastasis. We first applied the bioinformatic approaches to determine the potential miRNAs that are predicted to be related to 7 metastasis-related genes, including MMP9, CCR2, CCL2, TGF $\beta-1$, TGF $\beta$ R2, IL8, and IL10 [18, 20-23]. From analysis of 3 different databases, including the Targetscan, miRDB and miRanda [24-26], we found 35 miRNAs that could target at least three of these 7 metastasis-related genes (Figure 2A). Then we applied the qPCR assay to validate the influence of these 35 predicted miRNAs by targeting the TR4 with TR4siRNA in C4-2, PC3 and CWR22Rv1 cells and results revealed that 4 miRNAs (miR-494-3p, miR-3691-3p, miR-373-3p and miR-3121-5p) were up-regulated in all 3 cell lines (Figure 2B). We then applied an opposite approach using overexpressed (OE) miRNAs in the C4-2 cells and found only miR-373-3p could suppress PCa cell invasion (Figure 2C), and knocking-down TR4 increased miR-373-3p expression in all 3 PCa cell lines (Figure 2D).

Importantly, we also found miR-373-3p expression was negatively correlated with TR4 expression with higher expression of miR-373-3p vs lower expression of TR4 in 6 different PCa cell lines (C4-2, PC3, CWR22Rv1 (22Rv1), VCaP, LNCaP and DU145) plus two normal prostate cell lines (RWPE-1 and BPH-1) (Figure 2E). Furthermore, we also examined the TR4 vs miR-373-3p expression in human PCa tissues, and found a significant negative correlation $(r=-0.505, p=0.012)$ between the TR4 expression vs miR-373-3p expression in $24 \mathrm{PCa}$ specimens (Figure 2F).

Together, results from Figure $2 \mathrm{~A}-2 \mathrm{~F}$ suggest that TR4 can negatively regulate miR-373-3p expression in the PCa cell lines and tissues.

\section{miR-373-3p decreases PCa cell invasion}

To examine the miR-373-3p effects on PCa cell invasion, we first stably transfected miR-373-3p using the lentivirus system and confirmed its expression in C4-2, PC3 and CWR22Rv1 cells (Figure 3A). We then performed invasion assay and found miR-373-3p could significantly suppress the PCa cell invasion in the 3 cell lines (Figure 3B).

Using another 3D invasion assay, we also confirmed that addition of miR-373-3p in C4-2 cells decreased cell invasion (Figure 3C).

Together, results from Figure 3A-3C suggest miR373-3p can decrease PCa cell invasion.

\section{TR4 increases PCa cell invasion via suppression of miR-373-3p}

To investigate whether miR-373-3p is involved in TR4-increased PCa cell invasion, we applied interruption approaches to see if targeting miR-373-3p might alter the TR4-increased PCa cell invasion. The results revealed that addition of miR-373-3p inhibitor increased PCa PC3 cell invasion (Figure 4A, upper right vs upper left and Figure 4B, lane 2 vs 1). Furthermore, knocking-down TR4 (sh-TR4) decreased PCa cell invasion (Figure 4A, lower left vs upper left and Figure 4B, lane 3 vs 1) and addition of miR-373-3p inhibitor partially reversed the sh-TR4 decreased $\mathrm{PCa}$ cell invasion (Figure 4A, lower right vs lower left and Figure 4B, lane 4 vs 3 ). 
A
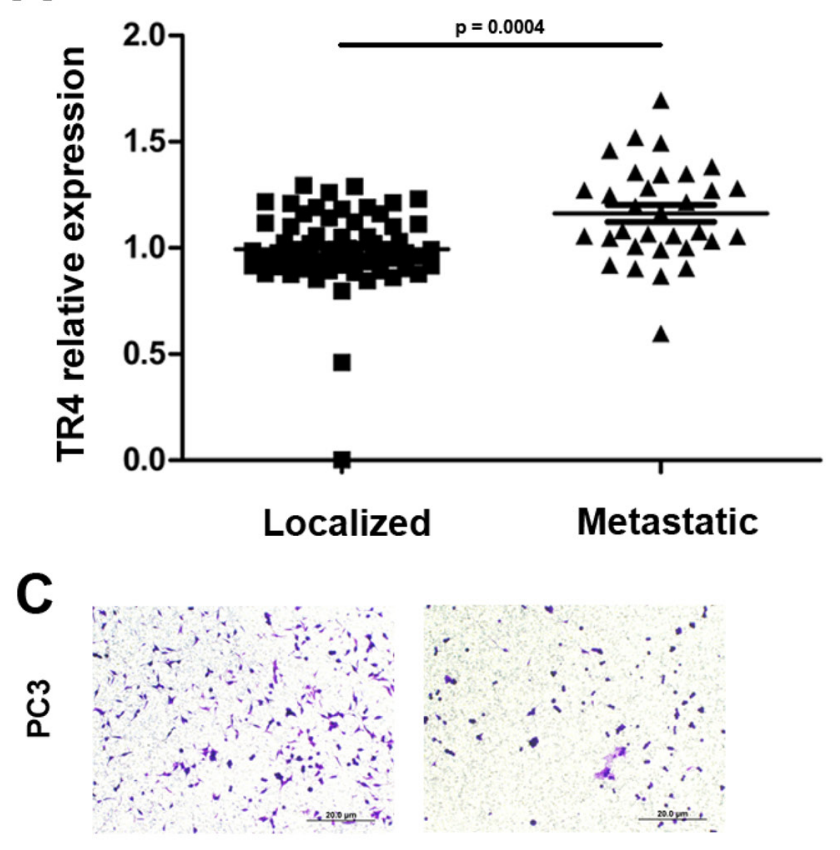

scr

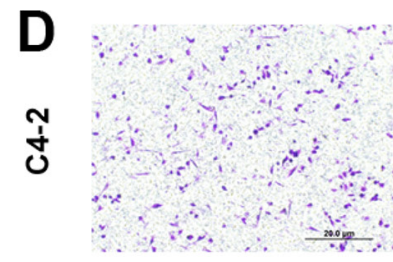

scr

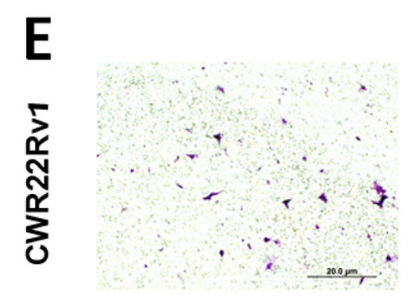

Vector

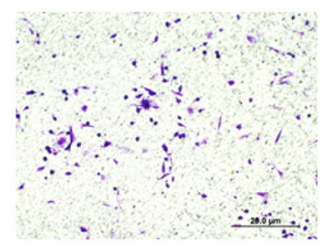

sh-TR4
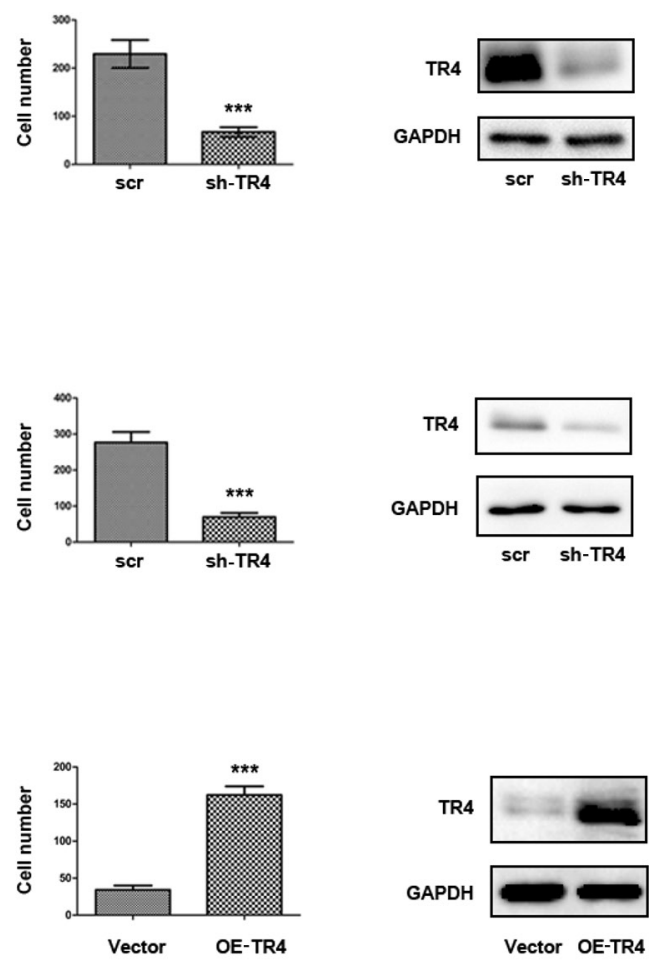

Figure 1: Effect of TR4 on PCa cell invasion. A. GEO databases to analyze the PCa sample array with TR4 expression revealed that PCa tissues $(n=32)$. B. The different expression of TR4 in three PCa cell lines. In PC3 cells, the expression is highest and in CWR22Rv1 (22Rv1) cells, it is the lowest. C-E. After $48 \mathrm{hrs}$ lentivirus transfection, cell were sded in cell invasion chambers with the inner wells coated with Matrigel and incubated for 24-36 hrs. Left panels: Representative microphotographs of invaded cells (100 $\times)$. Middle panels: Quantitive analysis (cell numbers were counted in six randomly chosen microscopic fields per membrane). ${ }^{* * *} p<0.001$ Right panels: Western blot analysis for the knockdown or overexpression of TR4. C-D. Invasion assays were performed in C4-2 (C) or PC3 (D) cells transfected with sh-TR4 or scramble control. E. Invasion assays were performed in CWR22Rv1 cells transfected with overexpressed TR4 (OE-TR4) and vector control.

We then applied the opposite approach in $\mathrm{C} 4-2$ cells to confirm the above findings. The results revealed that addition of miR-373-3p decreased C4-2 cell invasion (Figure 4C, upper right vs upper left and Figure 4D, lane 2 vs 1). Furthermore, addition of functional TR4 increased C4-2 cell invasion (Figure 4C, lower left vs upper left and Figure 4D, lane 3 vs 1) that could be reversed after adding miR-373-3p in C4-2 cells (Figure 4A, lower right vs lower left and Figure 4D, lane 4 vs 3 ).

Together, results from Figure 4A-4D suggest that TR4 may be able to function through inhibiting the miR-373-3p expression to increase PCa cell invasion. 
A

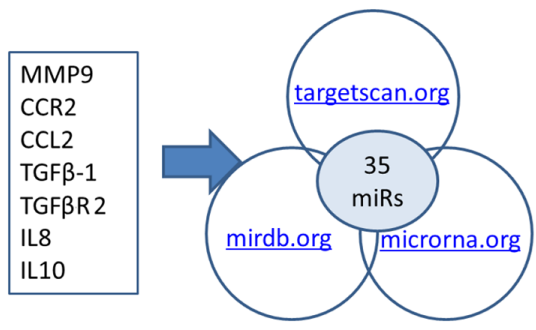

C

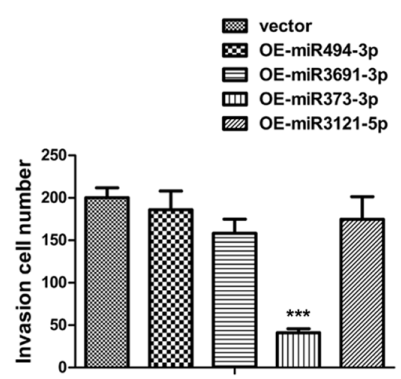

D

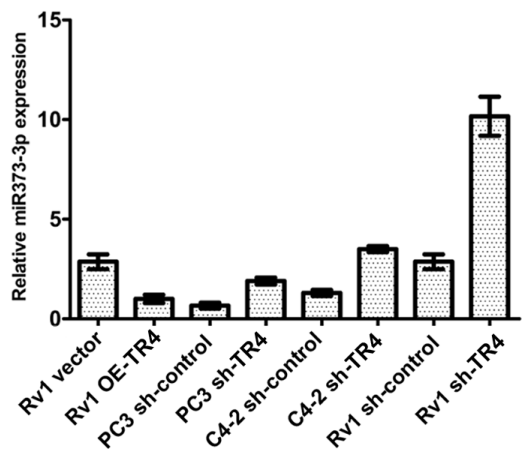

E

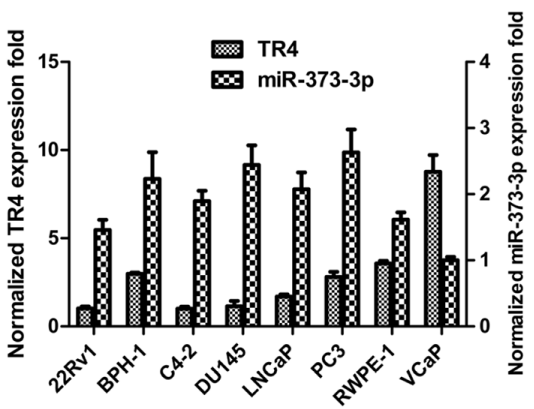

B

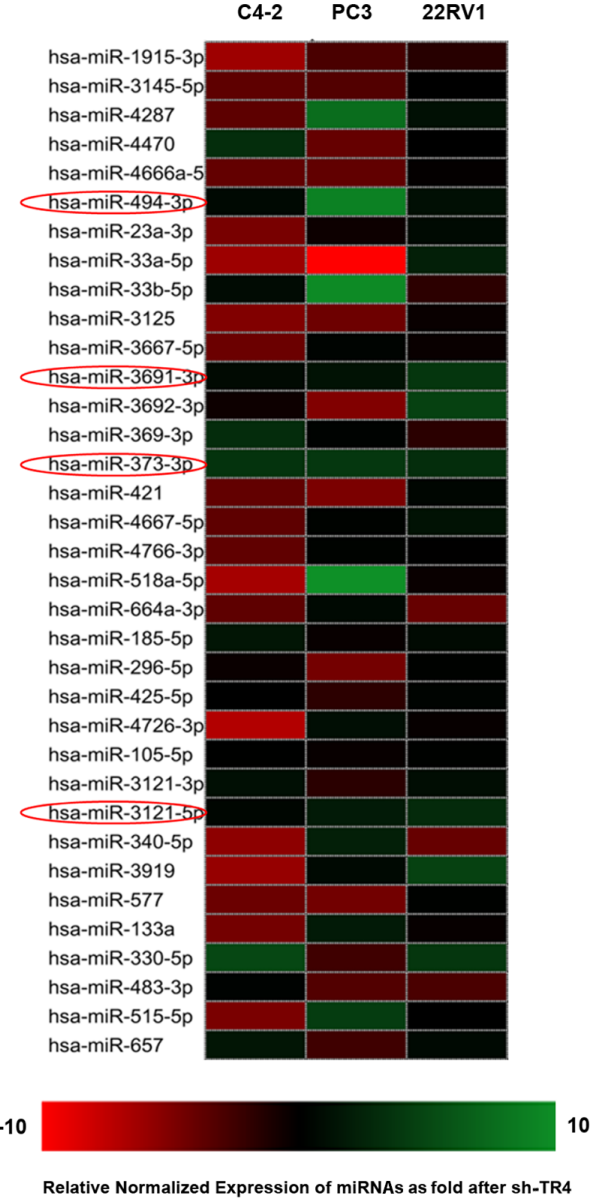

$\mathbf{F}$

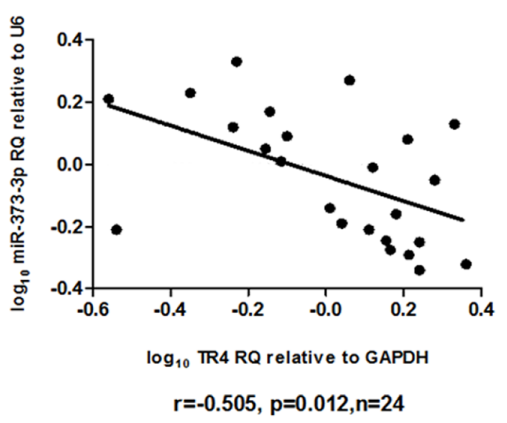

Figure 2: TR4 modulates miR-373-3p expression. A. Some genes related to TR4 or PCa metastasis from published articles $(20,22-25)$ were screened for microRNA. These genes included MMP9, CCR2, CCL2, TGFß-1, TGFßR2, IL8 and IL10. We picked out 35 overlapping miRNAs that target at least 3 of these putative genes from 3 microRNA prediction databases, targetscan.org, mirdb.org and microrna.org. B. Real-time PCR of 35 miRNAs related to PCa metastasis screened for si-TR4 in C4-2, PC3, and CWR22Rv1 cells. Relative normalized expression of miRNAs after knocking down TR4 was shown by different colors. When more green, the gene has a more negative correlation, the more red, the gene has a more positive correlation. There are 4 miRNAs up-regulated by TR4-siRNA in all 3 cell lines. C. We overexpressed (OE) the above miRNAs in the C4-2 cells with lentivirus transfection and found only miR-373-3p could suppress invasion $(* * * P<0.001)$. D. Real-time PCR (quantification) of miR-373-3p relative to U6 vector expression for shTR4 in C4-2, PC3, CWR22Rv1 (Rv1) cells and overexpressed TR4 in CWR22Rv1 (Rv1) cells. E. Comparison of real-time PCR expression (quantification) between miR-373-3p relative to U6 vector and TR4 relative to GAPDH in 8 human prostate cell lines. F. Plot of fold change of miR-373-3p related to fold change of TR4 in $24 \mathrm{PCa}$ samples; $\mathrm{RQ}=$ relative quantity, $r=-0.505$, Pearson correlation coefficient. 


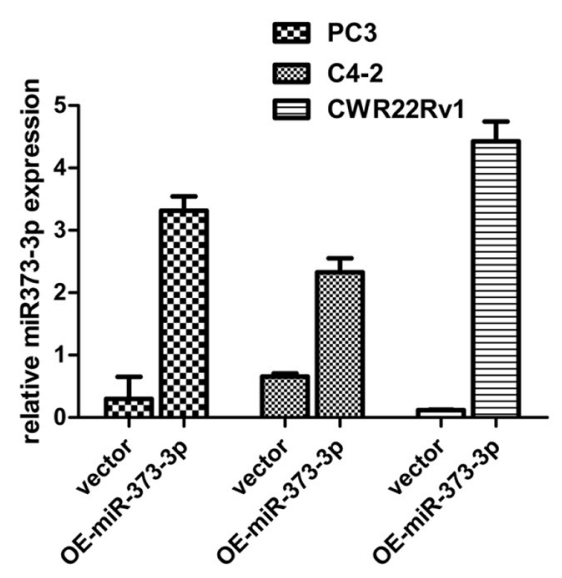

B
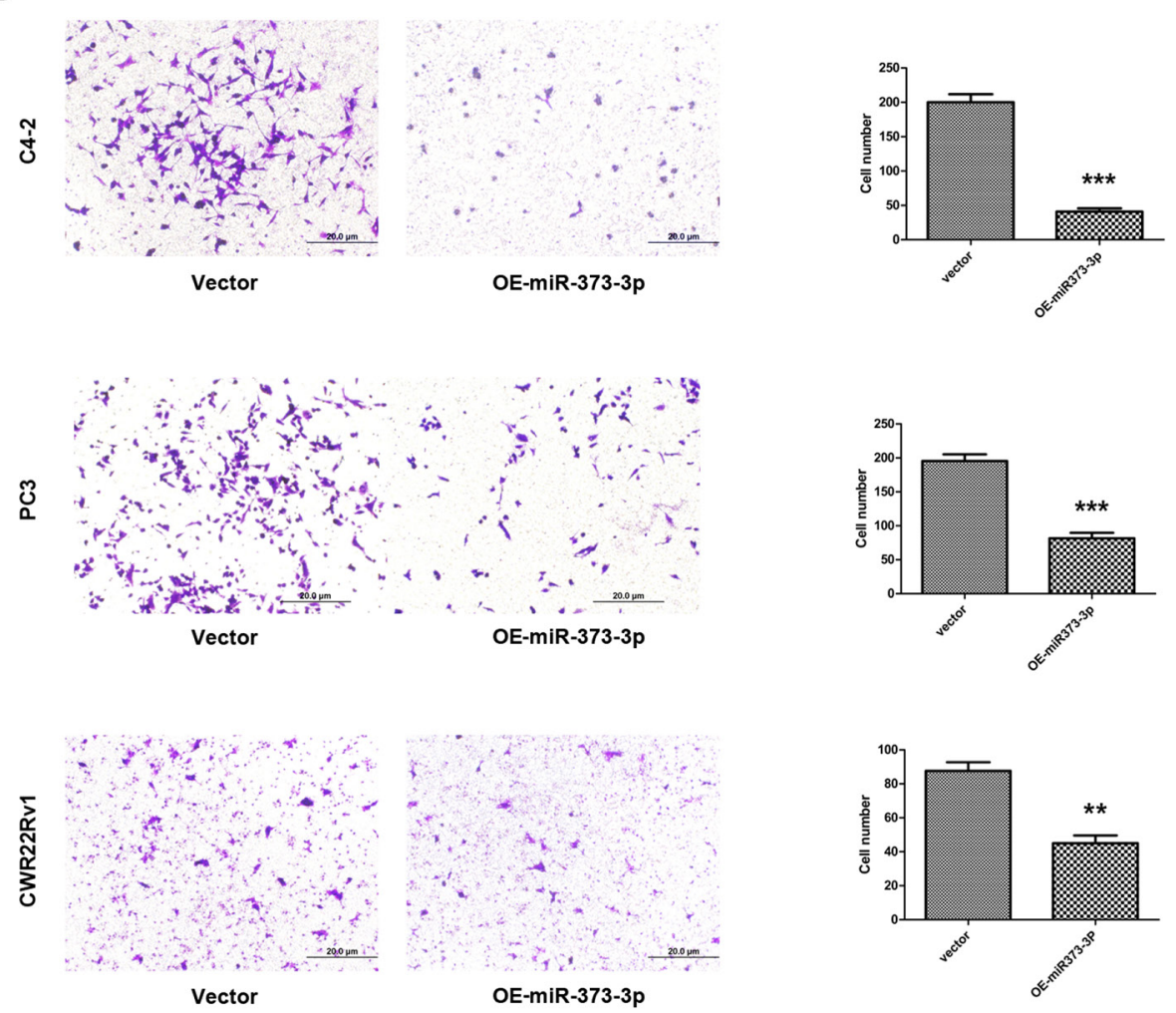

C
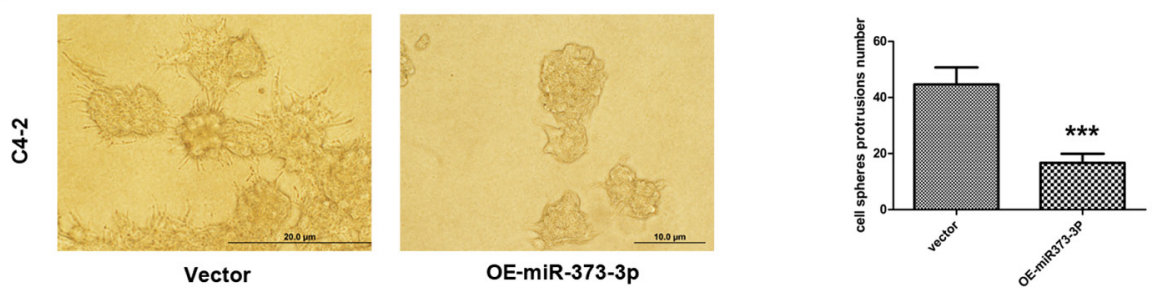

Figure 3: Effect of miR-373-3p on PCa cell invasion. A-C. After stable lentivirus transfection, cells were seeded in a cell invasion chamber with the inner well coated with Matrigel and incubated for 24-36 h. A. Real-time PCR test expression (quantification) of miR373-3p relative to U6 vector for stable overexpression (OE) of miR-373-3p in C4-2, PC3, and CWR22Rv1 cells. B. Invasion assay was performed in C4-2, PC3, CWR22Rv1 cells transfected with OE miR-373-3p or vector. Left: Representative microphotographs of invaded cells (magnification, $100 \times$ ). Right: Quantitative analysis (cell numbers were counted in six randomly chosen microscopic fields per membrane). C. 3D spheroid invasion assay was performed in C4-2 cells transfected with OE-miR-373-3p or vector. Left: Representative microphotographs of cells (magnification, $200 \times$ ). Right: Quantitative analysis (cell spheroid protrusions numbers were counted in six randomly chosen microscopic fields per membrane).*** $P<0.001, * * P<0.01$. 
A

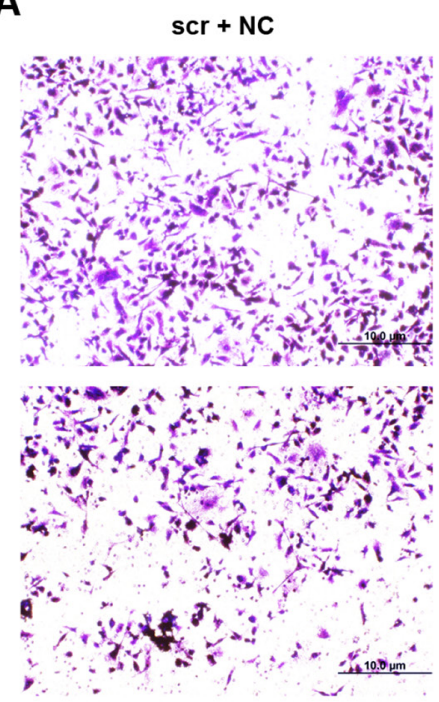

sh-TR4 +NC

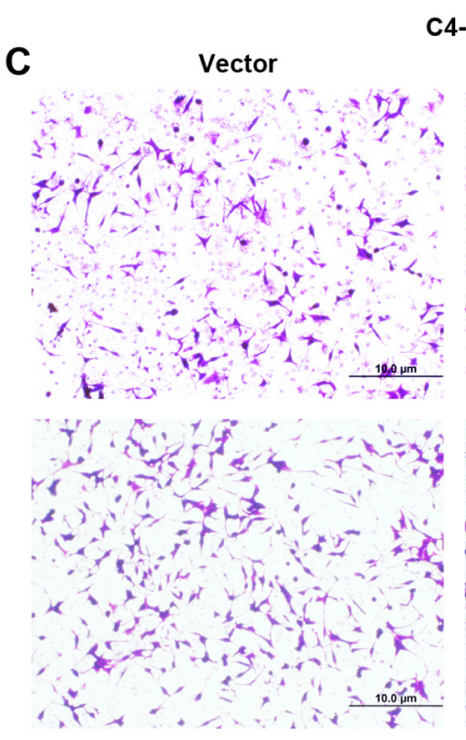

OE-TR4 + Vector
PC3

scr + miR-373-3p inhibitor
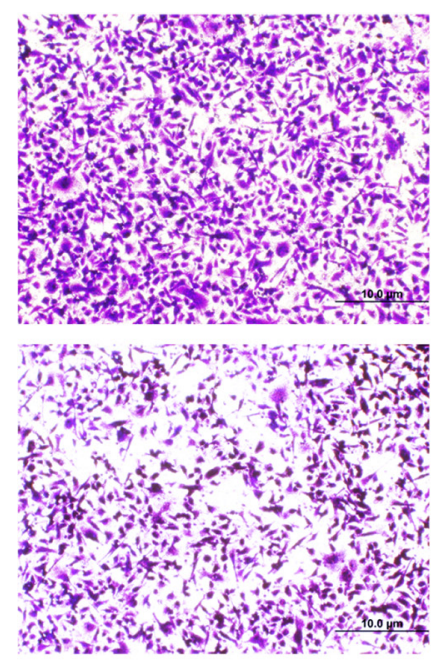

sh-TR4 + miR-373-3p inhibitor

4-2
B
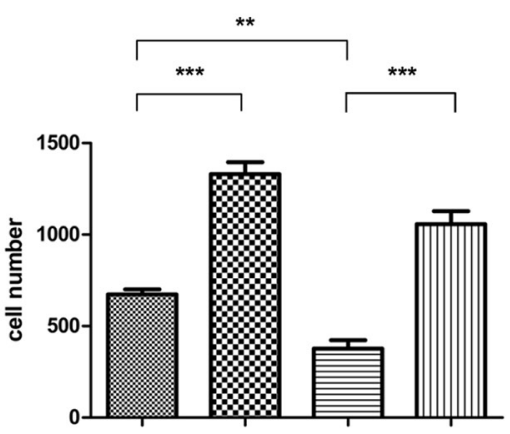

sh-TR4

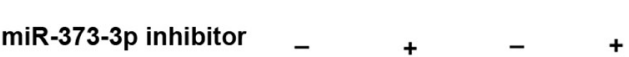

Figure 4: miR373-3p partially reverses TR4 function. After $24 \mathrm{~h}$ lentivirus transfection, plasmid transient transfection by lipofectamine was performed. After $48 \mathrm{~h}$, cells were seeded in cell invasion chambers with the inner wells coated with matrigel and incubated for 24-36 h. A. Invasion assay was performed in PC3 cells treated in 4 ways, scramble (scr) + negative control (NC), sh-TR4 + negative control, scr + miR-373-3p inhibitor and sh-TR4 + miR-373-3p inhibitor. Representative microphotographs of invaded cells (magnification, $100 \times$ ). B. Quantitative analysis for the 4 PC3 groups (cell numbers were counted in six randomly chosen microscopic fields per membrane). C. Invasion assay was performed in C4-2 cells treated in 4 ways, vector, vector + OE-miR-373-3p, OE-TR4 + vector, and OE-TR4 + OE-miR-373-3p. Representative microphotographs of invaded cells (magnification, $100 \times$ ). D. Quantitative analysis for the 4 C4-2 groups (cell numbers were counted in six randomly chosen microscopic fields per membrane).*** $P<0.001, * * P<0.01$.

\section{TR4 regulates the TGF $\beta R 2 / p-S m a d 3$ signals via decreasing the miR-373-3p expression}

To further dissect the molecular mechanism(s) how miR-373-3p functions as a tumor suppressor to mediate the TR4-increased PCa cell invasion, we analyzed the miRNA prediction databases and found the linkage of miR-373-3p to TGF $\beta$ R2 signals showing 4 potential positions to be targeted by miR-373-3p (Figure 5A). We then applied the luciferase assay to verify, and results revealed that addition of miR-373$3 p$ mimic decreased the luciferase activity of TGF $\beta R 2-3^{\prime}$ UTR that is linked to the luciferase (Figure 5B). We also applied the western blot to confirm the protein expression and found addition of miR-373-3p decreased the expression of TGF $3 R 2$ and its downstream p-Smad3 in PC3, C4-2 and CWR22Rv1 cells (Figure 5C).

To link the miR-373-3p-suppressed TGF $\beta R 2 /$ p-Smad3 to TR4, we knocked down TR4 with sh-TR4 
A

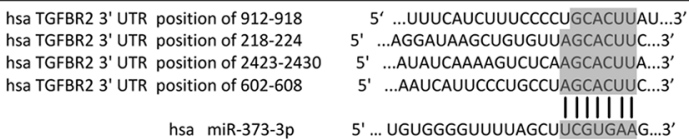

B

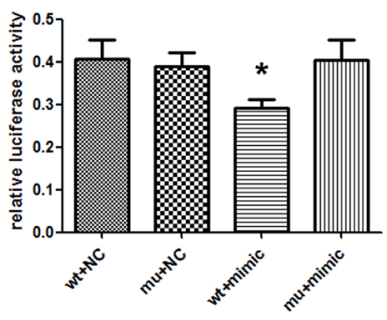

C

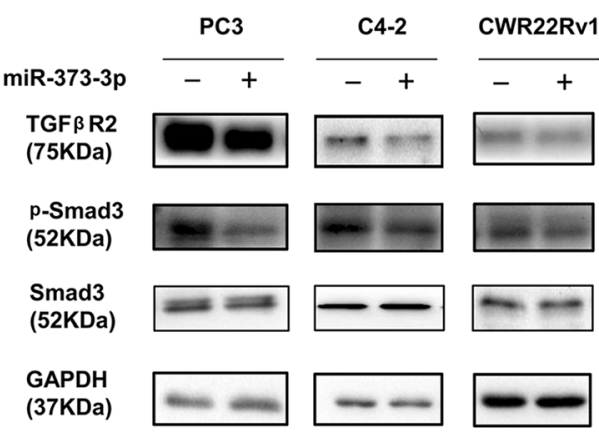

D

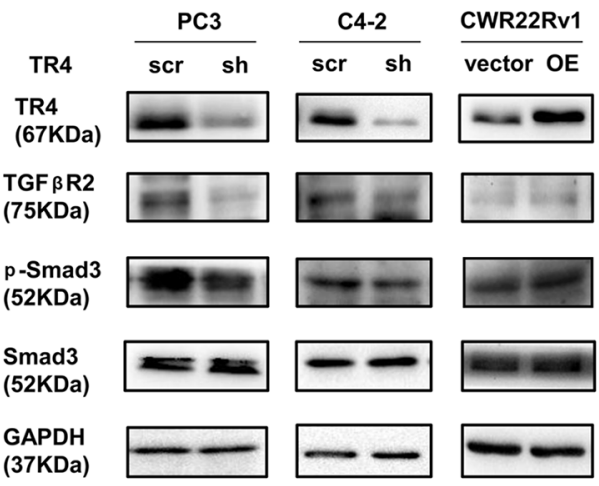

G

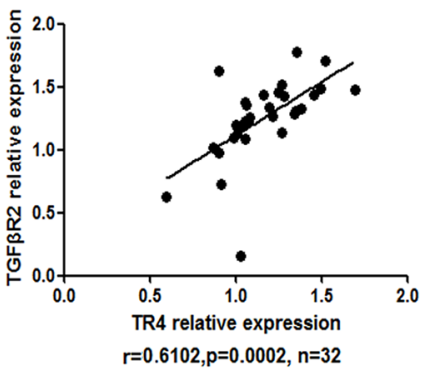

Figure 5: TR4 regulates the TGFßR2/p-Smad3 signals pathway via miR-373-3p. A. Predicted duplex formation between human TGFßR2 3' UTR and human miR-373-3p. There might be 4 target positions for miR-373-3p in TGFßR2 $3^{\prime}$ UTR. B. Luciferase assay was performed with four groups; 1) psiCHECK-2-TGFßR2-wt 3' UTR, 2) psiCHECK-2-TGFßR2-m3 3' UTR, 3) TGF $\beta R 2$-wt $33^{\prime}$ UTR + miR-373-3p mimic and 4) TGFßR2-m3_3' UTR + miR-373-3p mimic. C. Western blot analysis for TGFßR2, p-Smad3 of total lysates of PC3, C4-2, CWR22Rv1 cells with vector (-) or overexpressed (+) miR-373-3p lentivirus transfection for 72-96 h. GAPDH was used to determine equal loading. D. Western blot analysis for TR4, TGFBR2, p-Smad3 of total lysates of PC3, C4-2, CWR22Rv1 cells treated with scramble (scr) and knocked down TR4 (sh) or vector and overexpressed (OE) TR4 lentivirus transfection for 72-96 h. GAPDH was used to determine equal loading. E. After $24 \mathrm{~h}$ lentivirus transfection of sh-TR4 and pLKO in PCa cells, miR-373-3p inhibitor transient transfection by lipofectamine was performed. After $48-72 \mathrm{~h}$, protein was extracted for Western blot analysis. GAPDH was used to determine equal loading. F. After $24 \mathrm{~h}$ lentivirus transfection of overexpressed TR4 and vector in C4-2 and CWR22Rv1 cells, miR-373-3p mimic transient transfection by lipofectamine was performed. After $48-72 \mathrm{~h}$, protein was extracted to do Western blot analysis. GAPDH was used to determine equal loading. G. Using NCBI GEO databases to analyze the PCa sample array (GEO dataset accession GSE35988), this data shows that TR4 and TGF $\beta$ R2 expression in 32 metastasis PCa samples are positively correlated. $P=0.0002, r=0.6102$. Pearson correlation coefficient.

and results revealed that decreased TR4 suppressed the expression of TGF $\beta R 2$ and $\mathrm{p}-\mathrm{Smad} 3$ at the protein level in PC3 and C4-2 cells, and overexpressing TR4 in CWR22Rv1 increased the expression of TGF $\beta$ R2 and p-Smad3 at the protein level (Figure 5D). Importantly, we found the sh-TR4-suppressed TGF $\beta$ R2 and p-Smad3 expressions (Figure 5E, lane 3 vs 1) could be significantly reversed after addition of miR-373-3p inhibitor in PC3 cells (Figure 5E, lane 4 vs 3 ). As expected, TR4 enhanced TGF $\beta R 2$ and p-Smad 3 expression (Figure 5F, lane 3 vs 1) could be partially reversed after addition of miR-373-3p mimic in C4-2 cells (Figure 5F, lane 4 vs 3). 
Using NCBI GEO databases to analyze the PCa sample array (GEO dataset accession GSE35988) [19], we also found the positive correlation $(r=0.6102, p=0.0002)$ of TR4 and TGF $\beta R 2$ in 32 metastatic PCa samples (Figure 5G).

Together, results from Figure $5 \mathrm{~A}-\mathrm{G}$ demonstrated that TR4 might function through inhibiting miR-373-3p to regulate TGF $\beta R 2 / p-S m a d 3$ signals to increase PCa cell invasion.

\section{TR4 increases PCa metastasis via suppression miR-373-3p-TGFßR2 signals in vivo}

To further confirm the above in vitro data in an in vivo mouse model, we first stably transfected CWR22Rv1 cells with firefly luciferase reporter gene (Luc-CWR22Rc1) and prepared cell lines transduced with vector, OE-TR4, and OE-TR4 + OE-miR-373-3p, and orthotopically xenografted cells $\left(10^{6}\right)$ into anterior prostates of 10 mice/group. After 6 weeks IVIS images revealed that the mice with overexpressed TR 4 cells had more metastatic foci than mice injected with vector cells (Figure 6A-6B). Importantly, injecting mice with cells overexpressing both miR-373-3p and TR4 then reversed the increased meastatic foci formation (Figure 6A-6B).

$\mathrm{H} \& \mathrm{E}$ staining of those metastatic foci confirmed that the metastatic foci found in diaphragm, pelvic wall and hepatic region were indeed PCa (Figure 6C). RT-qPCR assay confirmed that miR-373-3p expression in mice with overexpressed TR4 was lower and in mice with overexpressed TR4 plus miR-373-3p was higher (Figure $6 \mathrm{D})$. IHC staining for TR4 and TGF $\beta$ R2 were also in agreement with in vitro results (Figure 6E).

Together, results from Figure $6 \mathrm{~A}-6 \mathrm{E}$ in vivo mouse model studies are in agreement with the above in vitro cell lines studies and demonstrated that targeting TR4 could suppress PCa cell invasion via regulation of miR-373-3p/ TGF $\beta R 2 / p-S m a d 3$ signals.

\section{DISCUSSION}

Although ADT is the standard treatment for advanced PCa, most patients eventually relapse with castration resistance [2-4]. Interestingly, recent studies also indicated some ADT might enhance PCa metastasis [27]. Among several signals that affect the PCa progression, we found that TR4 might play a protective role to suppress the prostate tumorigenesis, knockingout TR4 might increase PIN and/or prostatic carcinoma formation [12], and targeting TR4 with lentiviral silencing might alter the chemo-resistance of $\mathrm{PCa}$ stem/progenitor cells [28]. In contrast, a recent study indicated that TR4 might play positive roles to increase $\mathrm{PCa}$ metastasis [18]. However, the detailed mechanisms, especially the linkage of miRNAs to TR4 positive roles to increase PCa metastasis, remain unclear. Here we demonstrated that TR4 could increase PCa cell invasion via inhibition of
miR-373-3p, suggesting TR4 might play dual roles with a suppressor role in $\mathrm{PCa}$ initiation and a promoter role in metastasis development.

As a key player in PCa, TR4 may have multiple ways to either modulate or to be modulated by miRNAs. Here we screened 35 miRNAs and found some of them are regulated by TR4 in PCa. Interestingly, we found miR373-3p might function as a suppressor to inhibit TR4. Early studies suggested that miR-373-3p might function as a potential novel oncogene in testicular germ-cell tumors [29] and breast cancer [30]. However, other studies reported that miR-373-3p could also function as a tumor suppressor in breast tumor [31] and pancreatic cancer [32]. These studies suggest that miR-373-3p has dual roles as both promoter and suppressor in different types of tumors.

Interestingly, early studies also suggested TGF $\beta$ signaling might play dual roles as a suppressor and a promoter to influence the tumor progression $[33,34]$. The loss of TGF $\beta$ R2 is associated with poor clinical prognosis and is a predictor of poor prognosis in early stage breast cancer but overexpression of the TGF $\beta$ ligand is associated with the metastatic phenotype in many tumors $[35,36]$, and Davies et al. reported that TGF $\beta$ enhanced metastasis in Ras-transfected human malignant epidermal keratinocytes [37].

Our previous study found that TR4 could promote PCa metastasis via modulation of the CCL2/CCR2 signals, a key player of EMT [18]. In this study we further found that TR4 could increase PCa cells invasion via inhibiting miR-373-3p and consequently enhance the TGF $\beta R 2 / p-$ Smad3 signals. These results suggest that TR4 may increase PCa metastasis through multiple mechanisms: not only the regular ligands/receptors, but also intercellular miRNAs/mRNAs. Similar phenomena also occurred in p53 signals showing p53 could modulate $\mathrm{Bcl} 2$ at the transcriptional level to regulate cell apoptosis, and at the same time p53 could also function through the miR34 family to regulate the apoptosis [38].

Our results showing TR4 might function as suppressor through modulation of miR-373-3p to alter the expression of TGF $\beta$ R $2 / \mathrm{p}-\mathrm{Smad} 3$ to increase the PCa metastasis, therefore represents the 3rd molecule (in addition to miR-373-3p and TGF $\beta$ ) in this newly identified pathway that has both suppressor and stimulator roles to influence the tumor metastasis. These complicated signals found in PCa suggest that the PCa metastasis process may be very hard to inhibit and targeting any particular molecule might be only effective in some and not all conditions.

To summarize, the studies presented herein demonstrate that TR4 might be able to function through inhibiting the miR-373-3p expression to alter the TGF $\beta$ R2/ p-Smad3 signals to increase the PCa cell invasion. Targeting TR4, miR-373-3p or TGF $\beta R 2 / p-S m a d 3$ may become a new potential therapeutic approach to better suppress PCa metastasis. 
A
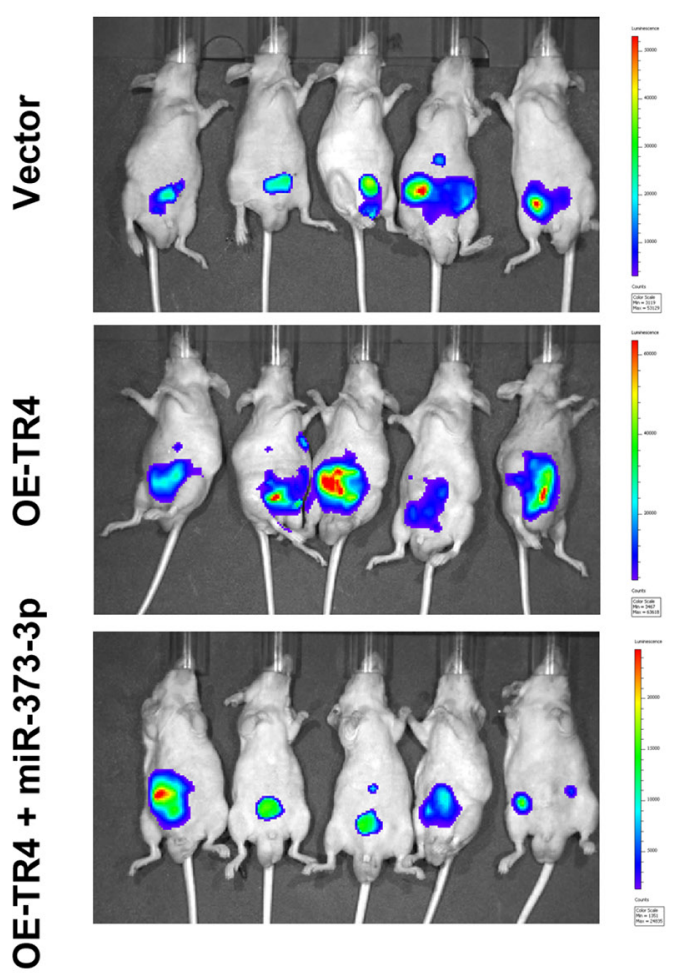

E
B

C

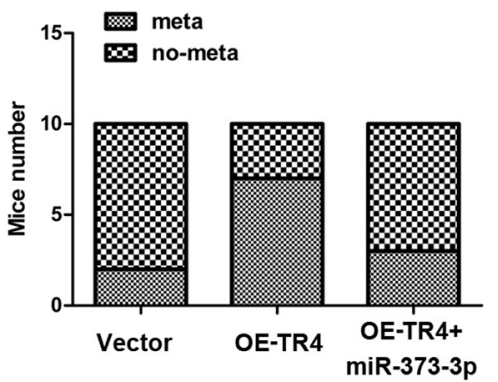

Metastasis sites

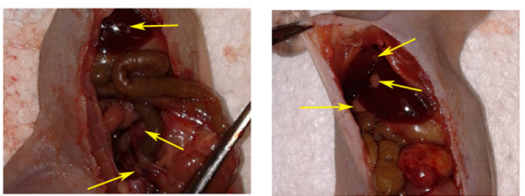

H \& E
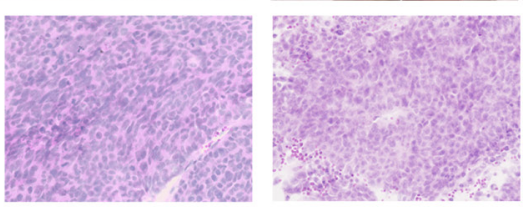

D

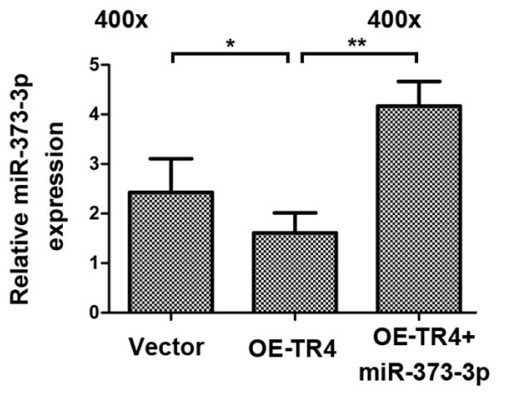

Vector

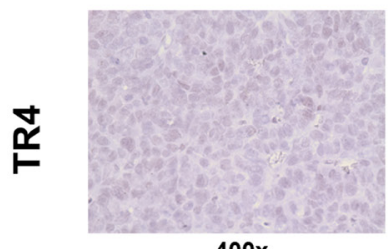

$400 x$

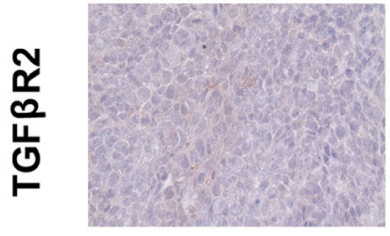

$400 x$

\section{OE-TR4}

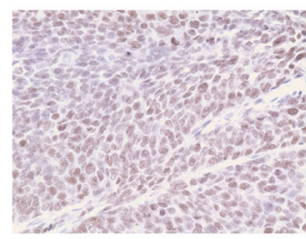

$400 x$

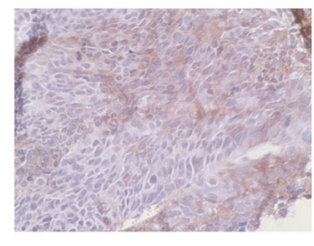

$400 x$
OE-TR4 + miR-373-3p

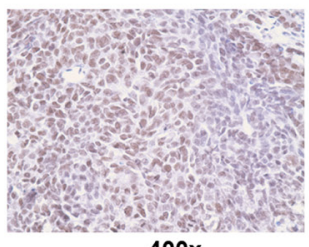

$400 x$

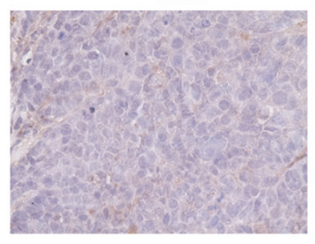

$400 x$

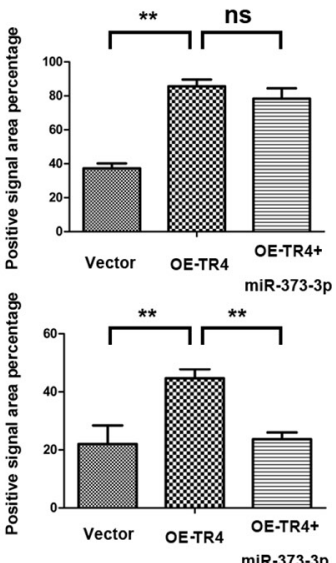

Figure 6: TR4 promotes metastasis of PCa via miR-373-3p in vivo. The CWR22Rv1 cells transduced with vector, overexpressed (OE)-TR4, or OE-TR4 + miR-373-3p were orthotopically implanted into the anterior prostates of nude mice. After 6 weeks implantation, the PCa growth and metastasis were monitored by IVIS images, following tail vein injection of Luciferin, and the mice were then sacrificed. Then H\&E and IHC tissue staining confirmed the expression of genes. A. Representative IVIS images six weeks after implanting CWR22Rv1 cells into the anterior prostates of nude mice. B. Incidence of metastases in different groups of mice at six weeks after cells implantation. C. Representative images of mouse with pelvic lymph node metastasis and with diaphragm metastasis (upper panels) and H\&E staining (lower panels) of metastatic foci are shown. D. RT-QPCR assay detecting miR-373-3p expression in 3 groups. ${ }^{*} p<0.05$, ${ }^{* *} p<0.01$. E. IHC staining for detecting TR4 (upper panels) and TGF $\beta$ R2 (lower panels) expressions in tumor tissues obtained from 3 groups mice. Quantification at right. $* * P<0.01$, ns no significance. 


\section{MATERIALS AND METHODS}

\section{Cell culture}

Human PCa cell lines C4-2, CWR22Rv-1, PC3, DU145, VCaP, and LNCaP, and human benign prostate cell lines RWPE-1 and BPH-1 were obtained from the American Type Culture collection (ATCC, Rockville, MD). RWPE-1 cells were maintained in complete keratinocyte serum-free media (KSF-M), supplemented with $1 \%$ penicillin/streptomycin/amphoterycin B, $50 \mathrm{mg} / \mathrm{ml}$ bovine pituitary extract and $5 \mathrm{ng} / \mathrm{ml}$ epidermal growth factor (Life Technologies, Barcelona, Spain). C4-2, CWR22Rv-1, $\mathrm{VCaP}, \mathrm{LNCaP}$, and BPH-1 cells were cultured in RPMI1640 media containing $1 \%$ penicillin and streptomycin, supplemented with $10 \%$ fetal bovine serum (FBS). PC3 and DU145 cells were cultured in DMEM media containing $1 \%$ penicillin and streptomycin, supplemented with $10 \%$ FBS. All cell lines were cultured in a $5 \%(\mathrm{v} / \mathrm{v})$ $\mathrm{CO}_{2}$ humidified incubator at $37^{\circ} \mathrm{C}$.

\section{Construct/generate PCa cell lines with differential stable expression of TR4 and/or miR-373-3p}

The miRNA-373-3p expression plasmid was generated by cloning the genomic pre-miR-373-3p gene, with a 200-bp sequence on each flanking side, into retroviral transfer plasmid pWPI to generate plasmid pWPI-miR-373-3p, as in the previous report [27]. To generate overexpressed TR4, overexpressed miR-373-3p and TR4 knocked-down stable clones, C4-2, CWR22Rv-1, and $\mathrm{PC} 3$ cells were transfected with lentiviral vectors, pWPI-TR4/pWPI-Vec, pWPI-miR-373-3p/pWPI-Vec or pLKO1.0-TR4-si/pLKO1-scr, the psPAX2 packaging plasmid, and pMD2.G envelope plasmid, then transfected into 293T cells using the standard calcium phosphate transfection method for $48 \mathrm{hrs}$ to obtain the lentivirus soup that was collected and frozen in $-80^{\circ} \mathrm{C}$ for later use. The cells were transfected using the LipofectAMINE 3000 (Invitrogen) reverse transfection protocol, according to the manufacturer's instructions. The miR-373-3p mimic $(10 \mathrm{nM})$, miR-373-3p inhibitor $(10 \mathrm{nM})$ and negative control (NC) were from Qiagen (Valencia, CA).

\section{Quantitative real-time PCR}

For RNA extraction, total RNAs were isolated using Trizol reagent (Invitrogen, Grand Island, NY). 1-2 $\mu$ g of total RNA was subjected to reverse transcription using Superscript III transcriptase (Invitrogen). Quantitative real-time PCR (qRT-PCR) was conducted using a Bio-Rad CFX96 system with SYBR green to determine the mRNA expression level of a gene of interest. Expression levels were normalized to the expression of GAPDH mRNA. The primers for TR4 are: Forward: $5^{\prime}-\mathrm{TCC}$ CCA CGC ATC CAG ATA ATC-3'; and Reverse: 5'-GAT GTG AAA
ACA CTC AAT GGG C-3'. The primers for GAPDH are: Forward: 5'-GGA GCG AGA TCC CTC CAA AAT-3'; and Reverse: 5'-GGC TGT TGT CAT ACT TCT CAT GG-3'. The miRNAs were isolated using PureLink ${ }^{\circledR}$ miRNA kit. In brief, $50 \mathrm{ng}$ small RNAs were processed for poly A addition by adding 1 unit of polymerase with $1 \mathrm{mM}$ ATP in $1 \times \mathrm{RT}$ buffer at $37^{\circ} \mathrm{C}$ for $10 \mathrm{mins}$ in $10 \mu \mathrm{l}$ volume, and then heat inactivated at $95^{\circ} \mathrm{C}$ for 2 mins, then add $50 \mathrm{pmol}$ anchor primer up to $12.5 \mu \mathrm{l}$ and incubate at $65^{\circ} \mathrm{C}$ for 5 mins. For the last step of cDNA synthesis, add $2 \mu \mathrm{l} 5 \times$ RT buffer, $2 \mu \mathrm{l} 10 \mathrm{mM}$ dNTP, $1 \mu \mathrm{l}$ reverse transcriptase up to total of $20 \mu \mathrm{l}$ and incubate at $42^{\circ} \mathrm{C}$ for $1 \mathrm{hr}$. Quantitative real-time PCR was conducted using a Bio-Rad CFX96 system with FAM/FITC to determine the miRNA expression level. Expression levels were normalized to the expression of U6 RNA.

\section{Western blot analysis}

Cells were lysed in RIPA buffer and proteins $(20-50 \mu \mathrm{g})$ were separated on $8-10 \%$ SDS/PAGE gel and then transferred onto PVDF membranes (Millipore, Billerica, MA). After blocking membranes, they were incubated with appropriate dilutions of specific primary antibodies against GAPDH (Santa Cruz, \#sc-166574, Paso Robles, CA), TR4 (Perseus Proteomics, \#PP-H0107B-00), TGFßR2 (Abcam, \#ab17650, San Deigo, CA), p-Smad3 (Ser425, Santa Cruz, \#sc-11769) or Smad3 (Santa Cruz, \#sc-101154). The blots were incubated with HRPconjugated secondary antibodies and visualized using ECL system (Thermo Fisher Scientific, Rochester, NY).

\section{Invasion assay}

The invasion capabilities of $\mathrm{PCa}$ cells were determined by the transwell assays. To prepare chambers for assay, $10 \mathrm{~mL}$ of Matrigel (BD, Inc) was dissolved in $50 \mathrm{~mL}$ serum-free DMEM or RPMI-1640, and $100 \mu \mathrm{l}$ mixed Matrigel added to the upper chambers of transwells containing $8 \mu \mathrm{m}$-pore-size polycarbonate membrane filters (Corning, Inc., Corning, NY), and put into the incubator for $5 \mathrm{hrs}$. PCa cells were then harvested and seeded with serum-free DMEM or RPMI-1640 media into the upper chamber at $1 \times 10^{5}$ cells/well, and the bottom chambers contained DMEM or RPMI-1640 with $10 \%$ FBS, and then transwells were incubated for $48 \mathrm{hrs}$ at $37^{\circ} \mathrm{C}$. Following incubation, the invaded cells attached to the lower surface of the membrane were fixed using $4 \%$ paraformaldehyde and stained with $1 \%$ toluidine blue. Cell numbers were counted in six randomly chosen microscopic fields $(100 \times)$ per membrane.

\section{D invasion assay}

The 3D invasion assay was modified from the previous report [39]. Briefly, $1 \times 10^{4}$ of cells in $200 \mu \mathrm{l}$ media containing $1 \%$ Matrigel was plated into the 
collagen/Matrigel mixture coated 24-well plates. The media was replenished every 3 days for 2 wks and the spheres with/without protrusions recorded under microscope. 100 spheres were recorded in each well to determine the ratio of cells with/without protrusions.

\section{Luciferase reporter gene assays}

$1 \times 10^{3}$ of cells/well in 24-well plates were transfected with psiCHECK-2-TGF $\beta$ R2-wt 3' UTR (Addgene, Plasmid 31882), psiCHECK-2-TGFßR2-m3_3' UTR (Addgene, Plasmid 31883), TGFßR2-wt_3' UTR + miR-373-3p mimic (QIAGEN, Lot no:171418189) and TGFßR2-wt_3' UTR + miR-373-3p mimic using Lipofectamine 3000 (Invitrogen). After 48 hrs transfection, cell lysates were prepared with Passive Lysis Buffer (Promega, Madison, WI) and luciferase activities were measured using the Dual Luciferase Reporter Assay (Promega, Madison, WI).

\section{In vivo metastasis studies}

Male 6-8 weeks old athymic nude mice were purchased from NCI. 30 mice were divided into 3 groups. $1 \times 10^{6}$ cells (mixture with Matrigel, 1:1) were injected into the anterior prostate of all mice. Group 1 mice were injected with Luc-CWR22Rv1 cells transduced with vector, Group 2 mice with Luc-CWR22Rv1 cells transduced with overexpressed TR4, and Group 3 mice with Luc-CWR22Rv1 cells transduced with overexpressed TR4 and overexpressed miR-373-3p. Every week, tumor growth/metastasis was monitored by in vivo imaging system (IVIS Spectrum, Caliper Life Sciences, Hopkinton, MA) following tail vein injection of Luciferin. At the end of treatment ( 6 weeks), mice were sacrificed and tumor growth and metastases at lymph nodes as well as to distant organs were analyzed and examined by H\&E staining.

\section{H\&E and immunohistochemical (IHC) staining}

Tissues were fixed in $10 \%(\mathrm{v} / \mathrm{v})$ formaldehyde in PBS, embedded in paraffin, and cut into $4 \mu \mathrm{m}$ sections and used for H\&E staining and IHC staining with human TR4/TGF $\beta R 2$ antibodies. To enhance antigen exposure, the slides were treated with EDTA at $98^{\circ} \mathrm{C}$ for $10 \mathrm{~min}$ for antigen retrieval. The slides were incubated with endogenous peroxidase blocking solution to inhibit endogenous peroxidase, and then were incubated with the primary antibody at room temperature for $60 \mathrm{~min}$. After rinsing with Tris-buffered saline, the slides were incubated for 45 min with biotin-conjugated secondary antibody, washed, and then incubated with enzyme conjugate horseradish peroxidase (HRP)-streptavidin. Freshly prepared DAB (Zymed, South San Francisco, CA) was used as the substrate to detect HRP. Finally, slides were counter-stained with hematoxylin and mounted with aqueous mounting media.

\section{Statistical analysis}

Data are expressed as mean \pm SEM from at least 3 independent experiments. Statistical analyses involved paired $t$-test with SPSS 17.0 (SPSS Inc., Chicago, IL). For the in vivo studies, measurements of tumor metastasis among the three groups were analyzed through one-way ANOVA coupled with the Newman-Keuls test. $p<0.05$ was considered statistically significant.

\section{ACKNOWLEDGMENTS}

This study was supported by NIH grants (CA122840 and CA156700), George Whipple Professorship Endowment, the Taiwan Department of Health Clinical Trial Research Center of Excellence (DOH99TD-B-111-004 to China Medical University, Taichung, Taiwan). National Natural Science Foundation of China (Grant No. 81472776) and a project funded by the Priority Academic Program Development of Jiangsu Higher Education Institutions. We thank Karen Wolf for help preparing the manuscript.

\section{CONFLICTS OF INTEREST}

The authors declare no conflicts of interest.

\section{REFERENCES}

1. Siegel R, Naishadham D, Jemal A. Cancer statistics. CA Cancer J Clin. 2013; 63:11-30.

2. Wen S, Niu Y, Lee SO, Chang C. Androgen receptor (AR) positive vs negative roles in prostate cancer cell deaths including apoptosis, anoikis, entosis, necrosis and autophagic cell death. Cancer Treat Rev. 2014; 40:31-40.

3. Lin TH, Lee SO, Niu Y, Xu D, Liang L, Li L, Yeh SD, Fujimoto N, Yeh S, Chang C. Differential androgen deprivation therapies with anti-androgens casodex/bicalutamide or MDV3100 / Enzalutamide versus anti-androgen receptor ASC-J9(R) Lead to promotion versus suppression of prostate cancer metastasis. J Biol Chem. 2013; 288:19359-69.

4. Lee SO, Ma Z, Yeh CR, Luo J, Lin TH, Lai KP, Yamashita S, Liang L, Tian J, Li L, Jiang Q, Huang CK, Niu Y, Yeh S, Chang C. New therapy targeting differential androgen receptor signaling in prostate cancer stem/ progenitor vs. non-stem/progenitor cells. J Mol Cell Biol. 2013; Feb 5:14-26.

5. Chang C, Da Silva SL, Ideta R, Lee Y, Yeh S, Burbach JP. Human and rat TR4 orphan receptors specify a subclass of the steroid receptor superfamily. PNAS. 1994; 91:6040-6044.

6. Hirose T, Fujimoto W, Tamaai T, Kim KH, Matsuura H, Jetten AM. TAK1: molecular cloning and characterization of a new member of the nuclear receptor superfamily. Mol Endocrinol. 1994; 8:1667-1680. 
7. Lee YF, Lee HJ, Chang C. Recent advances in the TR2 and TR4 orphan receptors of the nuclear receptor superfamily. J Steroid Biochem Mol Biol. 2002; 81:291-308.

8. Yang $\mathrm{X}$, Downes $\mathrm{M}, \mathrm{Yu} \mathrm{RT}$, Bookout AL, He W, Straume M, Mangelsdorf DJ, Evans RM. Nuclear receptor expression links the circadian clock to metabolism. Cell. 2006; 126:801-810.

9. Xie S, Lee YF, Kim E, Chen LM, Ni J, Fang LY, Liu S, Lin SJ, Abe J, Berk B, Ho FM, Chang C. TR4 nuclear receptor functions as a fatty acid sensor to modulate CD36 expression and foam cell formation. PNAS. 2009; 106:13353-13358.

10. Lin SJ, Ho HC, Lee YF, Liu NC, Liu S, Li G, Shyr CR, Chang C. Reduced osteoblast activity in the mice lacking TR4 nuclear receptor leads to osteoporosis. Reprod Biol Endocrinol. 2012; 10:43.

11. Liu S, Lee YF, Chou S, Uno H, Li G, Brookes P, Massett MP, Wu Q, Chen LM, Chang C. Mice lacking TR4 nuclear receptor develop mitochondrial myopathy with deficiency in complex I. Mol Endocrinol. 2011; 25:1301-1310.

12. Lin SJ, Lee SO, Lee YF, Miyamoto H, Yang DR, Li G, Chang C. TR4 nuclear receptor functions as a tumor suppressor for prostate tumorigenesis via modulation of DNA damage/repair system. Carcinogenesis. 2014; 35:1399-406.

13. Niu Y, Wang J, Shang Z, Huang SP, Shyr CR, Yeh S, Chang C. Increased CK5/CK8-positive intermediate cells with stromal smooth muscle cell atrophy in the mice lacking prostate epithelial androgen receptor. PLoS One. 2011; 6:e20202.

14. Ikushima H, Miyazono K. TGFbeta signalling: a complex web in cancer progression. Nat Rev Cancer. 2010; 10:415-24.

15. Bartel DP. MicroRNAs: genomics, biogenesis, mechanism, and function. Cell. 2004; 23;116:281-97.

16. Lovat F, Valeri N, Croce CM. MicroRNAs in the pathogenesis of cancer. Semin Oncol. 2011; 38:724-33. Lovat, F, Valeri, N, Croce, CM. MicroRNAs in the pathogenesis of cancer.

17. Walter BA, Valera VA, Pinto PA, Merino MJ. Comprehensive microRNA Profiling of Prostate Cancer. J Cancer. 2013; 4:350-7.

18. Ding X, Yang DR, Lee SO, Chen YL, Xia LQ, Lin SJ, Yu SC, Niu YJ, Li G, Chang C. TR4 nuclear receptor promotes prostate cancer metastasis via up-regulation of CCL2/ CCR2 signaling. Int J Cancer. 2015; 136:955-64.

19. Grasso CS, Wu YM, Robinson DR, Cao X, Dhanasekaran SM, Khan AP, Quist MJ, Jing X, Lonigro RJ, Brenner JC, Asangani IA, Ateeq B, Chun SY, Siddiqui J, Sam L, Anstett M, Mehra R, Prensner JR, Palanisamy N, Ryslik GA, Vandin F, Raphael BJ, Kunju LP, Rhodes DR, Pienta KJ, Chinnaiyan AM, Tomlins SA. The mutational landscape of lethal castration-resistant prostate cancer. Nature. 2012; Jul 12;487:239-43.
20. Sun GG, Lu YF, Zhang J, Hu WN. Filamin A regulates MMP-9 expression and suppresses prostate cancer cell migration and invasion. Tumour Biol. 2014; 35:3819-26.

21. Stearns M, Wang M, Stearns M. Proteases and invasion by metastatic tumor-cells - clinical implications for prostatecancer. Int J Oncol. 1994; 4:1013-23.

22. Araki S, Omori Y, Lyn D, Singh RK, Meinbach DM, Sandman Y, Lokeshwar VB, Lokeshwar BL. Interleukin-8 is a molecular determinant of androgen independence and progression in prostate cancer. Cancer Res. 2007; 67:6854-62.

23. Stearns ME, Wang M, Hu Y, Garcia FU. Interleukin-0 activation of the interleukin-0E pathway and tissue inhibitor of metalloproteinase- expression is enhanced by proteasome inhibitors in primary prostate tumor lines. Mol Cancer Res. 2003; 1:631-42.

24. Lewis BP, Burge CB, Bartel DP. Conserved seed pairing, often flanked by adenosines, indicates that thousands of human genes are microRNA targets. Cell. 2005; 120:15-20.

25. Wang XW, El Naqa IM. Prediction of both conserved and nonconserved microRNA targets in animals. Bioinformatics. 2008; 24:325-32.

26. John B, Enright AJ, Aravin A, Tuschl T, Sander C, Marks DS. Human MicroRNA targets. Plos Biol. 2004; 2:1862-79.

27. Asangani IA, Dommeti VL, Wang X, Malik R, Cieslik M, Yang R, Escara-Wilke J, Wilder-Romans K, Dhanireddy S, Engelke C, Iyer MK, Jing X, Wu YM, Cao X, Qin ZS, Wang S, Feng FY, Chinnaiyan AM. Therapeutic targeting of BET bromodomain proteins in castration-resistant prostate cancer.Nature. 2014; 510:278-82.

28. Yang DR, Ding XF, Luo J, Shan YX, Wang R, Lin SJ, Li G, Huang CK, Zhu J, Chen Y, Lee SO, Chang C. Increased chemosensitivity via targeting testicular nuclear receptor 4 (TR4)-Oct4-interleukin 1 receptor antagonist (IL1Ra) axis in prostate cancer CD133 + stem/progenitor cells to battle prostate cancer. J Biol Chem. 2013; 288:16476-83.

29. Voorhoeve PM, le Sage C, Schrier M, Gillis AJ, Stoop H, Nagel R, Liu YP, van Duijse J, Drost J, Griekspoor A, Zlotorynski E, Yabuta N, De Vita G, Nojima H, Looijenga LH, Agami R. A genetic screen implicates miRNA-372 and miRNA-373 as oncogenes in testicular germ cell tumors. Cell. 2006; 124:1169-81.

30. Huang Q, Gumireddy K, Schrier M, le Sage C, Nagel R, Nair S, Egan DA, Li A, Huang G, Klein-Szanto AJ, Gimotty PA, Katsaros D, Coukos G, Zhang L, Puré E, Agami R. The microRNAs miR-373 and miR-520c promote tumour invasion and metastasis. Nat Cell Biol. 2008; 10:202-10.

31. Keklikoglou I, Koerner C, Schmidt C, Zhang JD, Heckmann D, Shavinskaya A, Allgayer H, Gückel B, Fehm T, Schneeweiss A, Sahin O, Wiemann S, Tschulena U. MicroRNA-520/373 family functions as a tumor suppressor in 
estrogen receptor negative breast cancer by targeting NF- $\mathrm{kB}$ and TGF- $\beta$ signaling pathways. Oncogene. 2012; 31:4150-63.

32. Nakata K, Ohuchida K, Mizumoto K, Aishima S, Oda Y, Nagai E, Tanaka M. Micro RNA-373 is Down-regulated in Pancreatic Cancer and Inhibits Cancer Cell Invasion. Ann Surg Oncol. 2014; 21:S564-74.

33. Chowdhury S, Ammanamanchi S, Howell GM. Epigenetic Targeting of Transforming Growth Factor $\beta$ Receptor, II, and Implications for Cancer Therapy. Mol Cell Pharmacol. 2009; 1:57-70.

34. Pardali K, Moustakas A. Actions of TGF-beta as tumor suppressor and pro-metastatic factor in human cancer. Biochim Biophys Acta. 2007; 1775:21-62.

35. Gobbi H, Dupont WD, Simpson JF, et al. Transforming growth factor-beta and breast cancer risk in women with mammary epithelial hyperplasia. J Natl Cancer Inst. 1999; 91:2096-101.
36. Gobbi H, Arteaga CL, Jensen RA, Simpson JF, Dupont WD, Olson SJ, Schuyler PA, Plummer WD Jr, Page DL. Loss of expression of transforming growth factor beta type II receptor correlates with high tumour grade in human breast in-situ and invasive carcinomas. Histopathology. 2000; 36:168-77.

37. Davies M, Prime SS, Eveson JW, Price N, Ganapathy A, D'Mello A, Paterson IC. Transforming growth factor- $\beta$ enhances invasion and metastasis in Ras-transfected humanmalignant epidermal keratinocytes. Int J Exp Pathol. 2012; 93:148-56.

38. Hermeking H. The miR-34 family in cancer and apoptosis. Cell Death Differ. 2010; 17:193-9.

39. Xiang B, Muthuswamy SK. Using three-dimensional acinar structures for molecular and cell biological assays. Methods Enzymol. 2006; 406:692-701. 